\title{
Anterior Coracoscapular Ligament as a Factor Predisposing to or Protective for Suprascapular Neuropathy
}

\author{
Michał Polguj, ${ }^{1}$ Marek Synder, ${ }^{2}$ Andrzej Borowski, ${ }^{2}$ Mariusz Wojciechowski, \\ Grzegorz Wysiadecki, ${ }^{4}$ and Mirosław Topol ${ }^{4}$ \\ ${ }^{1}$ Department of Angiology, Interfaculty Chair of Anatomy and Histology, \\ Medical University of Łódź, Narutowicza 60, 90-136 Łódź, Poland \\ ${ }^{2}$ Clinic of Orthopedic and Pediatric Orthopedics, Medical University of Łódź, 90-131 Łódź, Poland \\ ${ }^{3}$ Department of Orthopedy, Brüderkrankenhaus St. Josef Paderborn Clinic, University of Göttingen, \\ Germany Schlossplatz 2, Wilhelmsplatz 1, 37073 Göttingen, Germany \\ ${ }^{4}$ Department of Normal and Clinical Anatomy, Interfaculty Chair of Anatomy and Histology, \\ Medical University of Łódź, Narutowicza 60, 90-136 Łódź, Poland \\ Correspondence should be addressed to Michał Polguj; michal.polguj@umed.lodz.pl
}

Received 7 October 2016; Revised 18 November 2016; Accepted 30 November 2016

Academic Editor: Ayhan Cömert

Copyright (C) 2016 Michał Polguj et al. This is an open access article distributed under the Creative Commons Attribution License, which permits unrestricted use, distribution, and reproduction in any medium, provided the original work is properly cited.

\begin{abstract}
Suprascapular neuropathy is a pathology caused by injury or compression of the suprascapular nerve. As the nerve runs from the anterior to posterior side of the scapula, the hot point where it is most susceptible to both injury and compression is the suprascapular notch. A literature search reveals several potential predisposing morphological factors in this area. However the most recent reports indicate that the structures at the suprascapular notch region may also prevent nerve injury and compression. The role of the anterior coracoscapular ligament (ACSL) remains unclear. While some studies indicate that it may predispose to suprascapular neuropathy, the newest study proposes a protective function. The aim of the article was to review the function of the anterior coracoscapular ligament in the light of the most recent studies. An understanding of the role of the ligament is essential for arthroscopic and other surgical procedures of this area in order to avoid iatrogenic injury of the suprascapular nerve.
\end{abstract}

\section{Introduction}

In the 21st century, it is rare to hear of new discoveries in anatomy, one of the oldest scientific fields. However, in 2002, Avery et al. [1] became the first to describe the presence of an independent ligament extending on the anterior side of the suprascapular notch, below the superior transverse scapular ligament (STSL), which they named the anterior coracoscapular ligament (ACSL) (Figure 1). This discovery has particular clinical importance, in that it may be a new risk factor for suprascapular nerve entrapment syndrome [1-4]. The incidence of the ACSL varies from $18.8 \%$ to $60.0 \%$, with this number varying according to population [1-8].

The suprascapular notch region is the most common site of both compression and injury of the suprascapular nerve along its course $[9,10]$, known to be causes of suprascapular neuropathy (SSN) [9]. This pathology is characterised by chronic pain of the shoulder, instability of the arm (weakness of abduction and increased external rotation), and progressive atrophy of the supraspinatus and infraspinatus muscles [11]. It is also important from a demographic point of view, as it mainly occurs in patients under 35 years of age and may lead to disability $[9,10,12]$. The outcome of treatment depends on the length of time between the onset of symptoms and the decompression of the nerve $[12,13]$. The suprascapular nerve $(\mathrm{SN})$ innervates the supraspinatus and infraspinatus muscles and also supports sensory branches to the posterior side of the glenohumeral joint capsule and up to $70 \%$ of skin of the shoulder $[12,14,15]$. After distal block of suprascapular nerve, patients had a sensory deficit in the area below the scapular spine. After proximal block of this nerve, the sensory deficit spread to both medial and lateral sides above and below the 


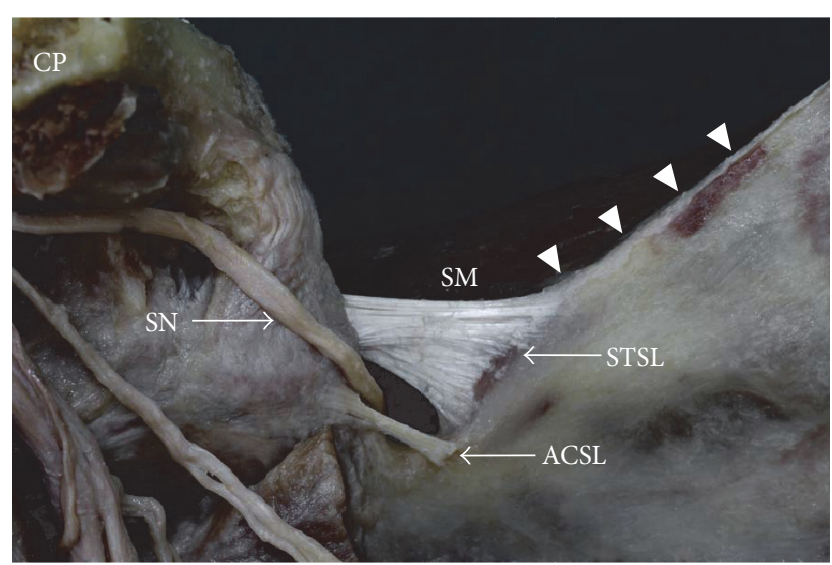

FIGURE 1: Formalin-fixed cadaveric shoulder focused on suprascapular region (band-shape ACSL); ACSL, anterior coracoscapular ligament; arrowhead, superior border of the scapula; CP, coracoid process; SN, suprascapular nerve; SM, supraspinatus muscle; STSL, superior transverse scapular ligament.

scapular spine [15]. Precise knowledge of the suprascapular notch region is crucial during arthroscopic procedures and open procedures of the shoulder region $[16,17]$. Therefore, an understanding of the morphological variations at this region is especially important for understanding etiopathology and endoscopic treatment of suprascapular nerve entrapment syndrome.

As knowledge of the role of the ACSL remains insufficient, the aim of the present study is to review the most recent observations concerning the factors exerting an influence on suprascapular neuropathy development.

\section{Epidemiology and Morphology of the ACSL}

A literature review reveals that the incidence of the anterior coracoscapular ligament varies globally according to region: $18.8 \%$ by Bayramoglu et al. [2] in a Turkish population, $28 \%$ by Piyawinijwong and Tantipoon [4] in a Thai population, $32 \%$ by Gürses et al. [3] in another Turkish population, $51.2 \%$ by Polguj et al. [5, 7] in a Polish population, $51.7-52 \%$ by Podgórski et al. $[6,8]$ in a Polish population, and $60 \%$ by Avery et al. [1] in an American population. In addition, the prevalence of ACSL may also vary among subpopulations, as demonstrated above in Turkey $(18.8-32 \%)[2,3]$ (Table 1).

Although the anatomy of the suprascapular region has been well investigated, there have been only two classifications of the morphology of the anterior coracoscapular ligament: one from 2012 by Piyawinijwong and Tantipoon [4] and another from 2013 by Polguj et al. [5].

Piyawinijwong and Tantipoon [4] found the anterior coracoscapular ligament to be present in four cases $(6 \%)$ bilaterally and 15 cases (22\%) unilaterally. A threefold classification according to the distal attachment of the ligament was proposed based only on macroscopic observation. In Type I, $(15.79 \%)$ the distal attachment extends to the anterior surface
TABLE 1: The occurrence of the anterior coracoscapular ligament (ACSL) according to population.

\begin{tabular}{|c|c|c|c|}
\hline Researchers & Country & $\begin{array}{c}\text { Frequency of } \\
\text { ACSL (\%) }\end{array}$ & $\begin{array}{c}\text { Number of } \\
\text { studied shoulders } \\
(n)\end{array}$ \\
\hline Bayramoglu et al. [2] & Turkey & $18.8 \%$ & 32 \\
\hline $\begin{array}{l}\text { Piyawinijwong and } \\
\text { Tantipoon [4] }\end{array}$ & Thailand & $28 \%$ & 127 \\
\hline Gürses et al. [3] & Turkey & $32 \%$ & 50 \\
\hline Podgórski et al. $[6,8]$ & Poland & $51.7 \%-52 \%$ & $60 / 100$ \\
\hline Polguj et al. $[5,7]$ & Poland & $51.2 \%$ & $84 / 86$ \\
\hline Avery et al. [1] & USA & $60 \%$ & 54 \\
\hline
\end{tabular}

of the scapula and passes onto the edge of the suprascapular notch. In Type II (63.16\%), the distal attachment extends across the suprascapular notch and subdivides the notch into two foramina. In Type III (21.05\%), the distal attachment lies near the bottom of the suprascapular notch.

Polguj et al. [5] described a simple quantitative classification of the ACSL based on specific geometrical parameters and morphology. The ACSL itself is classified according to maximal proximal width (MPW) and maximal distal width (MDW), with both sets of measurements being taken using two independent methods: classical osteometry and a procedure based on the analysis of digital photographic documentation. The analysis allowed the determination of four types of ACSL. In Type I (fan-shaped) (7\%), the diameters of the MPW and the MDW vary by more than two times. In Type II (band-shaped) (62.8\%), the diameters of the MPW and the MDW vary by less than two times. In Type III (bifid) (11.6\%) two independent bands are present at the medial edge of the suprascapular notch. In Type IV (vestigial) (18.6\%), the ligament is presented as a small band running in the area of the inferior border of the suprascapular notch.

In 2015, Gürses et al. [3] evaluated the topographical relationships between the suprascapular nerve, artery, and vein(s) to the ACSL, with ACSL morphology classified according to Polguj et al. as described above [5]. The ACSL were found to be uniformly fan-shaped in four shoulders (25\%), band-shaped in 11 shoulders $(68.7 \%)$, and vestigial in one shoulder $(6.3 \%)$. No bifid type ligaments were found. As a result, Gürses et al. [3] proposed another threefold classification, with one type divided into two subtypes. Type I is typified by a single suprascapular nerve passing between the STSL and ACSL (seven shoulders, 14\%). Type II is divided into subtypes IIa and IIb: Type IIa possessing a single suprascapular vein with a suprascapular nerve passing between the STSL and ACSL (six shoulders, 12\%) and Type IIb possessing a single suprascapular vein passing under the ACSL and a suprascapular nerve passing between the STSL and ACSL (one shoulder, 2\%). In Type III, the whole suprascapular triad (suprascapular artery, vein, and nerve) passes between the STSL and ACSL (two shoulders, $4 \%)$. 


\section{Anterior Coracoscapular Ligament as Factor Predisposing to or Protective for Suprascapular Neuropathy}

Avery et al. [1] and Bayramoglu et al. [2] found that the anterior coracoscapular ligament reduced the space available for the passage of the suprascapular nerve and postulated that the presence of this ligament may be a new factor contributing to suprascapular neuropathy. Piyawinijwong and Tantipoon [4] suggested that the presence of the ACSL (especially Type II and Type III according to their classification) could reduce the space available below the STSL and possibly cause suprascapular nerve entrapment. However, all three of the abovementioned studies $[1,2,4]$ were qualitative observations performed only at the macroscopic level, and a subsequent quantitative study failed to confirm this hypothesis [5]. In 2013, a cadaveric study of 84 embalmed adult human shoulders by Podgórski et al. [5] defined the area available for the passage of the suprascapular nerve through the suprascapular opening. The area was defined as being limited superiorly by the inferior border of the superior transverse scapular ligament, laterally and medially by the osseous walls of the suprascapular notch, and inferiorly by superior border of the anterior coracoscapular ligament or inferior border of the suprascapular notch (for specimens without an ACSL). The mean surface area of the suprascapular opening was found to be smaller $\left(29 \pm 18.4 \mathrm{~mm}^{2}\right)$ in specimens with an ACSL than in those where it was absent $\left(33.06 \pm 18.93 \mathrm{~mm}^{2}\right)$; however, this difference was found to be statistically insignificant ( $p=0.107$; Mann-Whitney test). Therefore, it could not be confirmed that the ACSL significantly reduced the space for the passage of the suprascapular nerve.

However, in our opinion, the situation is more complex and may depend on types of superior transverse scapular ligament (STSL), when the band-shape type of STSL coexisting with ACSL the mean surface area of the suprascapular opening was smaller $\left(19.7 \mathrm{~mm}^{2}\right)$ than in those without ACSL $\left(26.6 \mathrm{~mm}^{2}\right)$ [7]. On the other hand, in the fan-shaped type of STSL, the mean surface area of the suprascapular opening in shoulders with an ACSL was similar $\left(37.4 \mathrm{~mm}^{2}\right)$ to that found in shoulders without this structure $\left(36.1 \mathrm{~mm}^{2}\right)$ [7].

In etiopathology of suprascapular neuropathy formation, one of the most popular hypotheses is the "sling effect" proposed by Rengachary et al. [18]. It proposes that the suprascapular nerve makes minimal transitional movements during arm motion. An angulated nerve can be pressed against the borders of osteofibrous tunnel by the action of the upper limb. This repeated kinking irritates the nerve and induces microtrauma that can result in suprascapular neuropathy (Figure 2(a)). This hypothesis has been supported by observations on the morphology of the suprascapular notch $[18,19]$. A "deep" and narrow V-shaped suprascapular notch is a factor predisposing to suprascapular neuropathy [18-20].

On the other hand, the high frequency of ACSL occurrence, reaching as high as $60 \%$ [1], suggests that it should have an important function. Its occurrence does not correspond with the low incidence of neuropathy. In 2013, Polguj et al. [5]

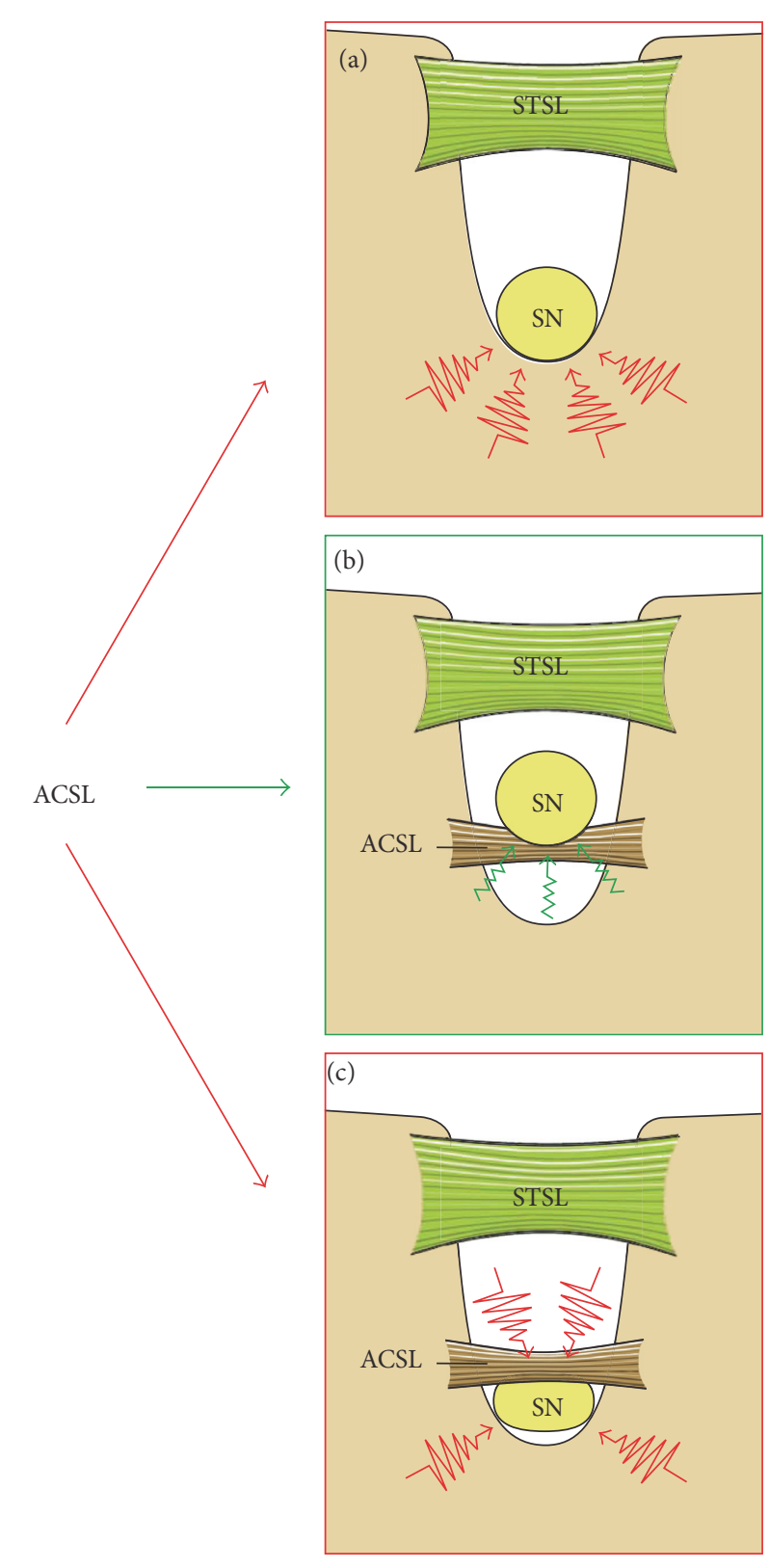

FIGURE 2: Schema presenting the predisposing (red arrows) or protective (green arrow) roles of the ACSL. In "deep and narrow" suprascapular notch (a), the nerve might be irritated by bony borders (red zigzag), but when the ACSL is present (b) the nerve might be protected by this ligament. When the nerve passes between the ACSL and the bottom of the suprascapular notch (c) it might be compressed (red zigzag). ACSL, anterior coracoscapular ligament; $\mathrm{SN}$, suprascapular nerve; STSL, superior transverse scapular ligament.

postulated that the presence of an ACSL may prevent from the development of suprascapular neuropathy, unless it does not significantly reduce the space under the STSL. Such a situation can be observed when the suprascapular nerve runs over the ACSL [5]; in that case, the ligament acts as a support for the nerve to protect it against excessive movement and forms a flume to enable direct passage of the nerve from the front 
side of the scapula to the supraspinatus fossa (Figure 2(b)). This hypothesis of the protective role of ACSL is supported by Podgórski et al. [6], who postulated that the ACSL is more common in the deep type of suprascapular notch, which is associated with a greater chance of suprascapular nerve entrapment syndrome (SNES) [14]. The presence of the ACSL beneath the nerve has been suggested to prevent irritation of the nerve by the bony border of the suprascapular notch. However, it is likely that the ACSL only plays a protective role in Types I-III according to Polguj et al. classification, in which it performs an actual mechanical function [6].

All the above suggests that the ACSL may play a protective role against this form of neuropathy (Figure 2(b)). It can support the suprascapular nerve, preventing its excessive movement and providing "tape cushioning." However, it is a hypothesis because there is no study in the literature that investigates the biomechanics of these ligaments (ACSL and STSL) during shoulder movements and their effects on nerve anatomy. Also it is necessary to remember that the pathogenesis of suprascapular neuropathy is complex and multifactorial and may depend on the variation and topography of the structures in the suprascapular notch region like arrangement of suprascapular nerve and vessels under STSL [21-23] or multiband of STSL [24, 25].

Recent studies suggested that the suprascapular notch is formed postnatally [26]. It is possible that the ACSL may play a protective role when a deep suprascapular notch is formed, as confirmed by the higher observed frequency of coexistence between deep suprascapular notches and the ACSL [6].

However, when the suprascapular nerve passes below the ACSL, it should be regarded as a potential risk factor for suprascapular neuropathy. In this configuration, the suprascapular nerve is compressed between the anterior coracoscapular ligament and the borders of the suprascapular notch (Figure 2(c)), as confirmed by Polguj et al. [27] who reported compression of the suprascapular nerve by the ACSL. Although the diameter of the suprascapular nerve is typically $2-3 \mathrm{~mm}[28,29]$ they found the $\mathrm{SN}$ to be flattened with a width of $7.2 \mathrm{~mm}$, probably as a result of compression by the ACSL. In addition, as the ligament can be bandshaped, fan-shaped, bifid, or vestigial (Figures 1, 3-5), the morphology of the ACSL itself may also influence the degree of compression of the $\mathrm{SN}$.

A second potential situation when the ACSL may elicit suprascapular neuropathy is when it is completely ossified. However, no such case based on formalin-fixed cadaveric shoulders had been described in the literature at the time of writing. However, probably the ossification of the single bundle of ACSL explains coexistence of the suprascapular notch and the suprascapular foramen [30,31]. This anatomical variation potentially increased the risk of suprascapular nerve entrapment by nerve irritation of the bony margins during passage through the foramen and by a lack of the elasticity that the ACSL normally demonstrates [30].

The presence of a completely ossified superior transverse scapular ligament (STSL) is one of the most important predisposing factors for suprascapular neuropathy [24, 32, 33], suggesting that when the ACSL is ossified, it may also injure the nerve by irritation. Simultaneous ossification of

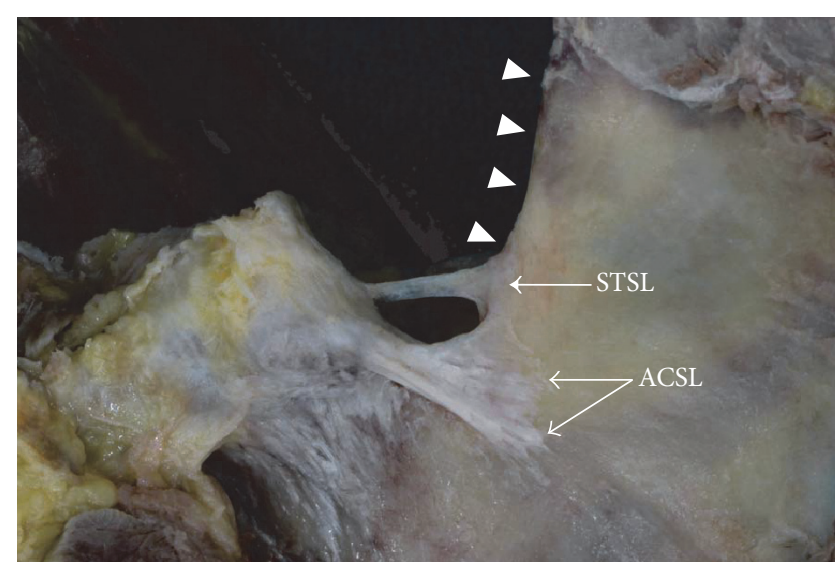

FIgURE 3: Formalin-fixed cadaveric shoulder focused on suprascapular region (fan-shape ACSL); ACSL, anterior coracoscapular ligament; arrowhead, superior border of the scapula; STSL, superior transverse scapular ligament.

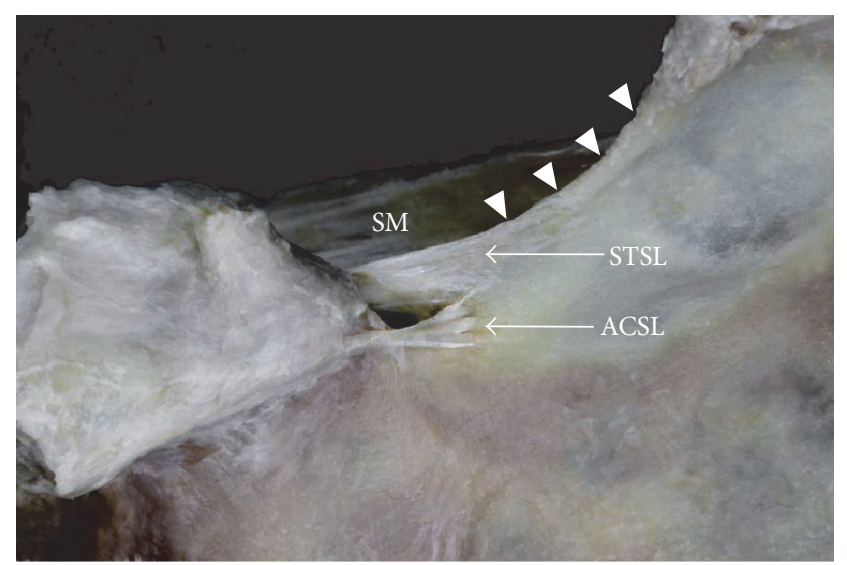

FIGURE 4: Formalin-fixed cadaveric shoulder focused on suprascapular region (bifid ACSL); ACSL, anterior coracoscapular ligament; arrowhead, superior border of the scapula; SM, supraspinatus muscle; STSL, superior transverse scapular ligament.

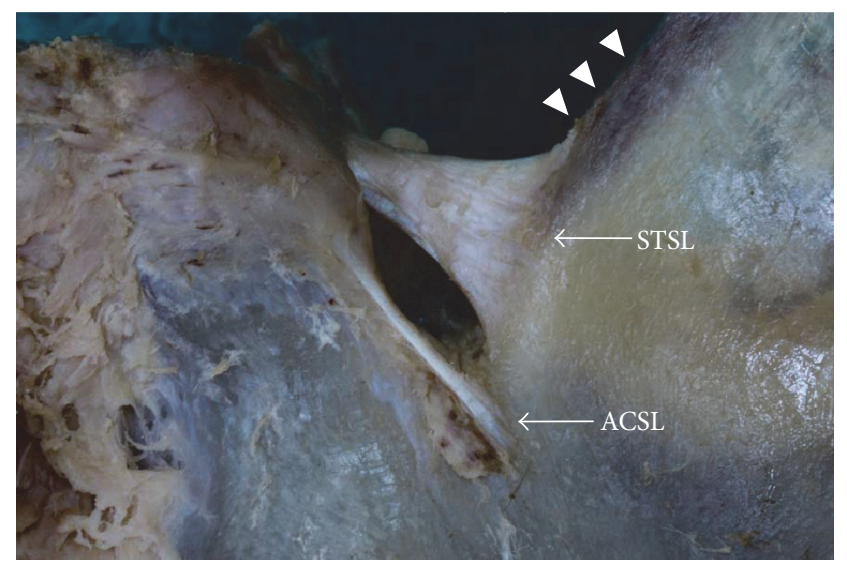

FIGURE 5: Formalin-fixed cadaveric shoulder focused on suprascapular region (vestigial ACSL); ACSL, anterior coracoscapular ligament; arrowhead, superior border of the scapula; STSL, superior transverse scapular ligament. 
the ACSL and the STSL should be proposed as the most probable explanatory mechanism of double suprascapular notch formation [34], a very rare anomaly. A double suprascapular foramen has been described in the literature only four times [34-37], and these reports indicate that the presence of two bony bridges may be a factor in the increased risk of occurrence of suprascapular neuropathy.

\section{Conclusion}

The role of the anterior coracoscapular ligament remains unclear. Its occurrence varies throughout the world and probably depends on population. Macroscopic, qualitative observations indicate that it may narrow the opening for the passage of the suprascapular nerve, potentially increasing the risk of suprascapular neuropathy. On the other hand, it may provide a mechanical barrier which protects the suprascapular nerve from injury. However, to improve this hypothesis the biomechanics investigation of the ligament during shoulder movements and its effects on nerve anatomy was necessary.

\section{Competing Interests}

The authors declare that they have no conflict of interests.

\section{References}

[1] B. W. Avery, F. M. Pilon, and J. K. Barclay, "Anterior coracoscapular ligament and suprascapular nerve entrapment," Clinical Anatomy, vol. 15, no. 6, pp. 383-386, 2002.

[2] A. Bayramoglu, D. Demiryürek, E. Tüccar et al., "Variations in anatomy at the suprascapular notch possibly causing suprascapular nerve entrapment: an anatomical study," Knee Surgery, Sports Traumatology, Arthroscopy, vol. 11, no. 6, pp. 393-398, 2003.

[3] I. A. Gürses, Ö. Gayretli, O. Coşkun, A. Kale, and A. Öztürk, "Anatomical relations between anterior coracoscapular ligament and suprascapular neurovascular structures and a proposal for classification," Acta Orthopaedica et Traumatologica Turcica, vol. 49, no. 4, pp. 433-437, 2015.

[4] S. Piyawinijwong and P. Tantipoon, "The anterior coracoscapular ligament in Thais: possible etiological factor of suprascapular nerve entrapment," Siriraj Medical Journal, vol. 64, pp. S12-S14, 2012.

[5] M. Polguj, K. Jędrzejewski, and M. Topol, "Variable morphology of the anterior coracoscapular ligament-a proposal of classification," Annals of Anatomy, vol. 195, no. 1, pp. 77-81, 2013.

[6] M. Podgórski, M. Topol, M. Sibiński, M. Domżalski, P. Grzelak, and M. Polguj, "What is the function of the anterior coracoscapular ligament?-a morphological study on the newest potential risk factor for suprascapular nerve entrapment," Annals of Anatomy, vol. 201, pp. 38-42, 2015.

[7] M. Polguj, K. Jedrzejewski, M. Podgórski, A. Majos, and M. Topol, "A proposal for classification of the superior transverse scapular ligament: variable morphology and its potential influence on suprascapular nerve entrapment," Journal of Shoulder and Elbow Surgery, vol. 22, no. 9, pp. 1265-1273, 2013.

[8] M. Podgórski, M. Sibiński, A. Majos, L. Stefańczyk, M. Topol, and M. Polguj, "The suprascapular vein: a possible etiology for suprascapular nerve entrapment and risk of complication during procedures around the suprascapular foramen region," Orthopaedics \& traumatology, surgery \& research: OTSR, vol. 100, no. 5, pp. 515-519, 2014.

[9] H. Zehetgruber, H. Noske, T. Lang, and C. Wurnig, "Suprascapular nerve entrapment. A meta-analysis," International Orthopaedics, vol. 26, no. 6, pp. 339-343, 2002.

[10] G. Antoniadis, H.-P. Richter, S. Rath, V. Braun, and G. Moese, "Suprascapular nerve entrapment: experience with 28 cases," Journal of Neurosurgery, vol. 85, no. 6, pp. 1020-1025, 1996.

[11] T. C. Moen, O. M. Babatunde, S. H. Hsu, C. S. Ahmad, and W. N. Levine, "Suprascapularneuropathy: what does the literature show?" Journal of Shoulder and Elbow Surgery, vol. 21, no. 6, pp. 835-846, 2012.

[12] R. E. Boykin, D. J. Friedman, L. D. Higgins, and J. J. P. Warner, "Suprascapular neuropathy," Journal of Bone and Joint Surgery A, vol. 92, no. 13, pp. 2348-2364, 2010.

[13] J. Gosk, M. Urban, and R. Rutowski, "Entrapment of the suprascapular nerve: anatomy, etiology, diagnosis, treatment," Ortopedia Traumatologia Rehabilitacja, vol. 9, no. 1, pp. 68-74, 2007.

[14] K. S. Harbaugh, R. Swenson, and R. L. Saunders, "Shoulder numbness in a patient with suprascapular nerve entrapment syndrome: cutaneous branch of the suprascapular nerve: case report," Neurosurgery, vol. 47, no. 6, pp. 1452-1456, 2000.

[15] C. Yoshioka, N. Suenaga, N. Oizumi, and S. Yamane, "Association of the area of sensory disturbance with the area of suprascapular nerve palsy," Journal of Orthopaedic Surgery, vol. 23, no. 3, pp. 304-308, 2016.

[16] D. N. Bhatia, J. F. de Beer, K. S. van Rooyen, and D. F. du Toit, "Arthroscopic suprascapular nerve decompression at the suprascapular notch," Arthroscopy-Journal of Arthroscopic and Related Surgery, vol. 22, no. 9, pp. 1009-1013, 2006.

[17] L. Lafosse, A. Tomasi, S. Corbett, G. Baier, K. Willems, and R. Gobezie, "Arthroscopic release of suprascapular nerve entrapment at the suprascapular notch: technique and preliminary results," Arthroscopy, vol. 23, no. 1, pp. 34-42, 2007.

[18] S. S. Rengachary, D. Burr, S. Lucas, K. M. Hassanein, M. P. Mohn, and H. Matzke, "Suprascapular entrapment neuropathy: a clinical, anatomical, and comparative study. II: anatomical study," Neurosurgery, vol. 5, no. 4, pp. 447-451, 1979.

[19] M. Dunkelgrun, K. Iesaka, S. S. Park, F. J. Kummer, and J. D. Zuckerman, "Interobserver reliability and intraobserver reproducibility in suprascapular notch typing," Bulletin: Hospital for Joint Diseases, vol. 61, no. 3-4, pp. 118-122, 2003.

[20] M. Polguj, M. Sibiński, A. Grzegorzewski, P. Grzelak, A. Majos, and M. Topol, "Variation in morphology of suprascapular notch as a factor of suprascapular nerve entrapment," International Orthopaedics, vol. 37, no. 11, pp. 2185-2192, 2013.

[21] J. R. Reineck and S. G. Krishnan, "Subligamentous suprascapular artery encountered during arthroscopic suprascapular nerve release: a report of three cases," Journal of Shoulder and Elbow Surgery, vol. 18, no. 3, pp. el-e3, 2009.

[22] M. Polguj, J. Rozniecki, M. Sibiński, A. Grzegorzewski, A. Majos, and M. Topol, "The variable morphology of suprascapular nerve and vessels at suprascapular notch: a proposal for classification and its potential clinical implications," Knee Surgery, Sports Traumatology, Arthroscopy, vol. 23, no. 5, pp. 1542-1548, 2015.

[23] C. Houtz and P. C. McCulloch, "Suprascapular vascular anomalies as a cause of suprascapular nerve compression," Orthopedics, vol. 36, no. 1, pp. 42-45, 2013. 
[24] M. Polguj, K. Jędrzejewski, A. Majos, and M. Topol, "Variations in bifid superior transverse scapular ligament as a possible factor of suprascapular entrapment: An Anatomical Study," International Orthopaedics, vol. 36, no. 10, pp. 2095-2100, 2012.

[25] M. Polguj, K. Jędrzejewski, A. Majos, and M. Topol, “The trifid superior transverse scapular ligament: a case report and review of the literature," Folia Morphologica (Warsz), vol. 71, no. 2, pp. 118-120, 2012.

[26] M. Podgórski, M. Polguj, M. Topol, A. Kusak, M. Łukaszewski, and P. Grzelak, "Suprascapular notch morphology in the pediatric population: a computed tomography study," Anatomical Science International, pp. 1-6, 2016.

[27] M. Polguj, K. Jędrzejewski, and M. Topol, “The bifid anterior coracoscapular ligament: a new morphological variation and its potential clinical implications," Folia Morphologica, vol. 71, no. 4, pp. 282-284, 2012.

[28] J. G. Edelson, "Bony bridges and other variations of the suprascapular notch," Journal of Bone and Joint Surgery - Series B, vol. 77, no. 3, pp. 505-506, 1995.

[29] D. Hirokawa, Y. Eliezri, E. Desciak, and C. Campanelli, "Suprascapular nerve injury during mohs surgery and review of the surgical anatomy of the nervous structures of the supraclavicular triangle," Dermatologic Surgery, vol. 36, no. 11, pp. 1756-1758, 2010.

[30] M. Polguj, K. Jędrzejewski, A. Majos, and M. Topol, "Coexistence of the suprascapular notch and the suprascapular foramen-a rare anatomical variation and a new hypothesis on its formation based on anatomical and radiological studies," Anatomical Science International, vol. 88, no. 3, pp. 156-162, 2013.

[31] K. Natsis, T. Totlis, P. Tsikaras, H. J. Appell, P. Skandalakis, and J. Koebke, "Proposal for classification of the suprascapular notch: a study on 423 dried scapulas," Clinical Anatomy, vol. 20, no. 2, pp. 135-139, 2007.

[32] S. B. Cohen, D. M. Dines, and C. T. Moorman III, "Familial calcification of the superior transverse scapular ligament causing neuropathy," Clinical Orthopaedics and Related Research, no. 334, pp. 131-135, 1997.

[33] M. Polguj, M. Sibiński, A. Grzegorzewski, M. Waszczykowski, A. Majos, and M. Topol, "Morphological and radiological study of ossified superior transverse scapular ligament as potential risk factor of suprascapular nerve entrapment," BioMed Research International, vol. 2014, Article ID 613601, 7 pages, 2014.

[34] M. Polguj, M. Podgórski, K. Jędrzejewski, and M. Topol, “The double suprascapular foramen: unique anatomical variation and the new hypothesis of its formation," Skeletal Radiology, vol. 41, no. 12, pp. 1631-1636, 2012.

[35] A. Hrdlička, "The adult scapula. Additional observations and measurements," American Journal of Physical Anthropology, vol. 29, no. 3, pp. 363-415, 1942.

[36] H.-J. Wang, C. Chen, L.-P. Wu, C.-Q. Pan, W.-J. Zhang, and Y.-K. Li, "Variable morphology of the suprascapular notch: an investigation and quantitative measurements in Chinese population," Clinical Anatomy, vol. 24, no. 1, pp. 47-55, 2011.

[37] P. Joy, M. B. Sinha, and B. C. Satapathy, "The ossified bifid superior transverse scapular ligament causing a double suprascapular foramen: a case report," Journal of Clinical and Diagnostic Research, vol. 9, no. 6, pp. AD03-AD04, 2015. 

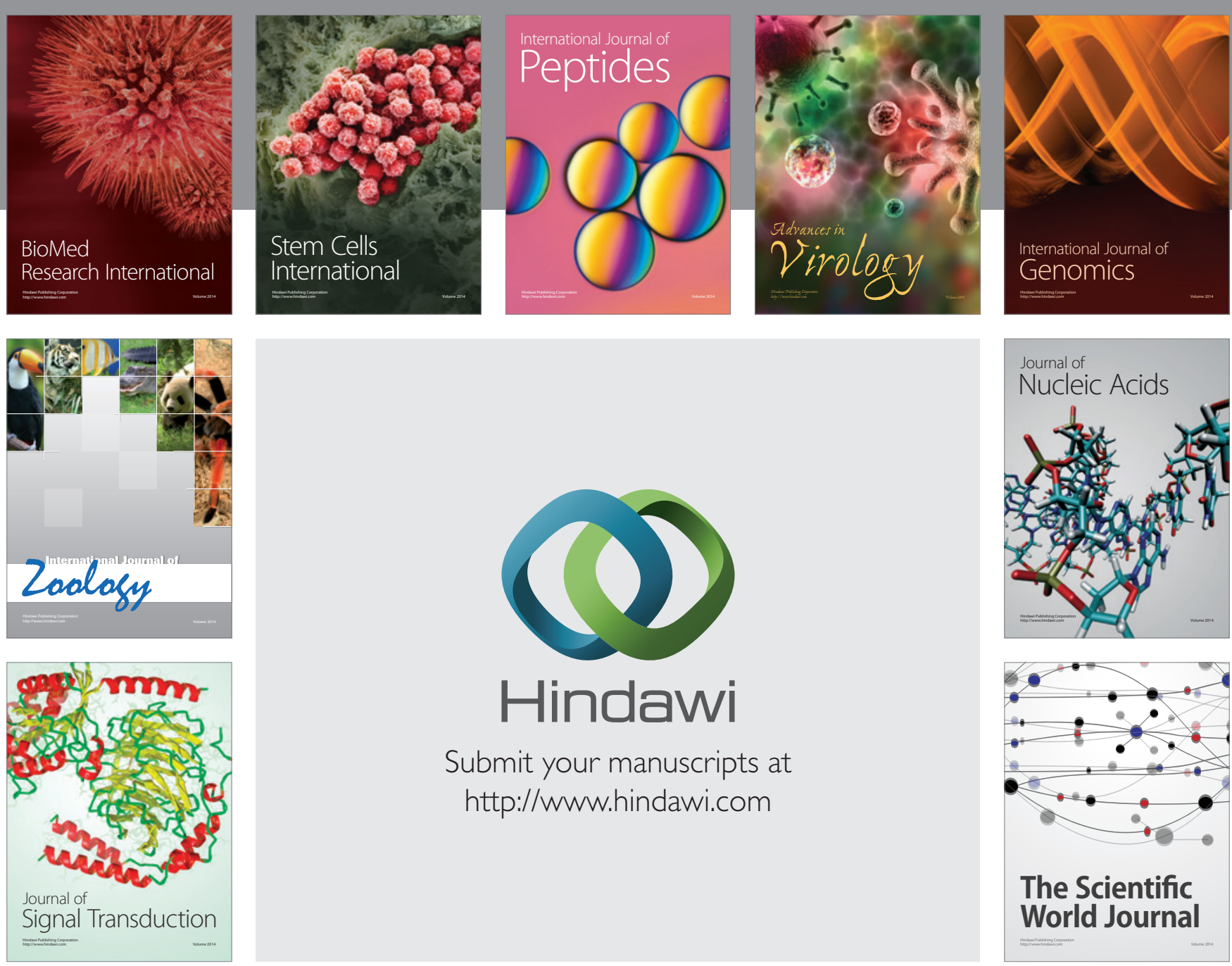

Submit your manuscripts at

http://www.hindawi.com
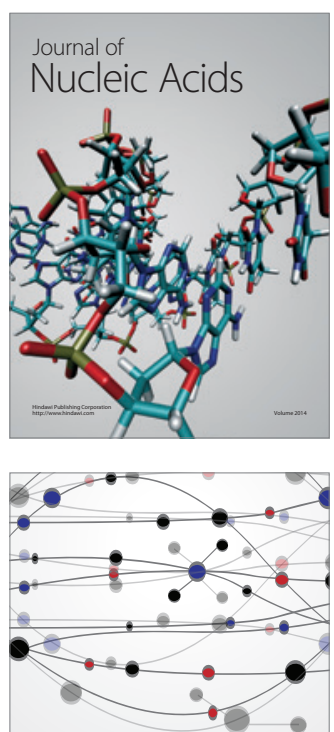

The Scientific World Journal
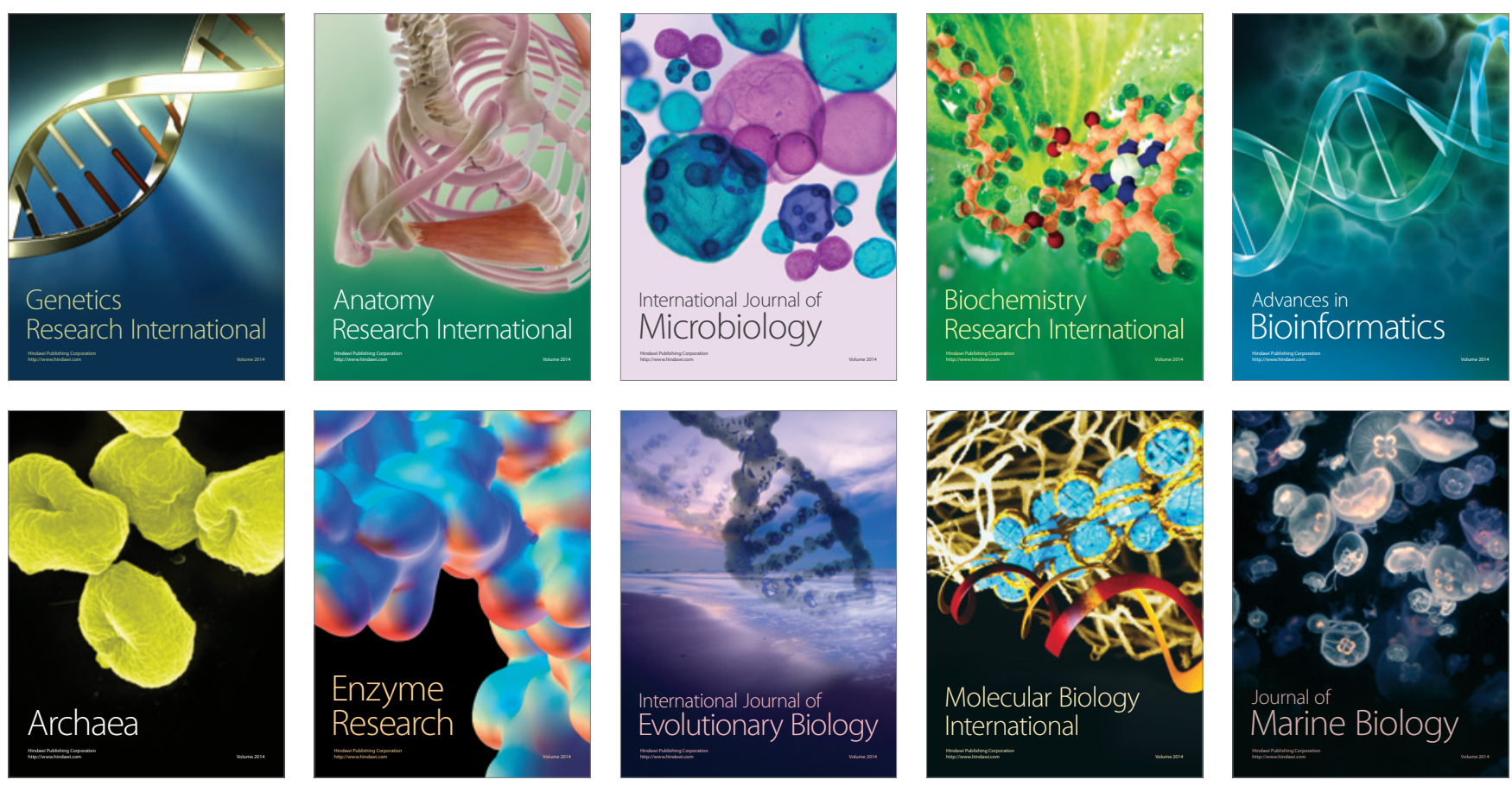